\title{
Tailoring macrocycles for metal ion binding
}

\author{
Leonard F. Lindoy \\ School of Chemistry, The University of Sydney, New South Wales 2006, Australia
}

\begin{abstract}
We have been concerned with the development of alternate strategies for achievins metalion recognition. An important aspect of this research has been to investigate meta! ion complexation over a range of related macrocycles, incorporating different macrocyclic ring sizes, donor atom set combinations and/or degree of ring substitution and to search for stability raxima at different points within this range. Assessment of the possible factors influencing any observed metal-ion recognition behaviour is then performed. This is followed by structural modification of particular ligand systems in an attempt to 'tune up' such behaviour. In particular instances it has proved possible to modify a ligand type progressively, using several 'tuning' cycles, such that very considerably enhanced discrimination towards a metal ion of interest has been achieved. In this manner, it has also proved possible to elucidate the subtle factors underlying different discrimination mechanisms. Studies of this type have tended to provide further insight into the factors influencing metal-ion discrimination than is normally possible for investigations involving a more limited ligand range.
\end{abstract}

\section{INTRODUCTION}

To achieve a ligand 'tailored' for a particular metal-ion binding application, the system needs to be designed such that it is able to read the 'information' encoded in the metal ion of interest and differentiate it from that for other metals that might also be present. Clearly, nature has learnt to do this superbly in a wide range of biochemical systems. In contrast, the success achieved with synthetic systems has tended to be somewhat more modest. This is perhaps surprising in view of the fact that we are now around a century on from Alfred Werner's time. Thus, although metal ion recognition is inherent to many processes in nature, the factors influencing such behaviour are often difficult to elucidate. This is especially the case when mixed donor sets are present and/or heavy metal ions are involved.

For a particular polydentate ligand, metal ion recognition may involve contributions from some or all of the following: the number and type of donor atoms available; their relative positions in terms of both their spacing and sequence within the ligand; the electronic and structural nature of the ligand's backbone; the formal charge and/or the presence or absence of dipoles (both permanent and induced) on the bound ligand; the number and size of the chelate rings formed on metal binding; and the changes in solvation of the ligand and metal ion on complex formation. Further, for transition metal ions, crystal field effects may also contribute to a decrease in free energy for complex formation. In the case of macrocyclic ligand systems, macrocyclic ring size is another factor that will influence complex stability (especially when the ring encircles the metal and is associated with the operation of a thermodynamic macrocyclic effect).

The ability of a given ligand to recognise a metal in the presence of others will normally reflect a subtle inix of factors on the type just mentioned (although, it is noted that, in some cases one factor, such as the donor set type, may appear to dominate the process). The situation is further complicated by the fact that several of the factors listed above are not independent of each other. However, in general terms, recognition for a particular metal ion of interest will occur when the properties of the ligand best match the steric and electronic nat ure of the metal, relative to those of the other metals present.

It needs to be kept in mind that metal ion selectivity depends on achieving a difference in the binding constants for the respective cations. That is, it is the difference in the constants, rather than their absolute magnitude, 
which is usually of prime concern. Of course, high absolute values may also be desirable since, for exanple, the latter may commonly be associated with enhanced kinetic stabilities.

How does one tackle the problem of achieving metal ion recognition? For some time we have been employing a simple strategy for obtaining such recognition and, more importantly, for understanding its nature when : $t$ was observed. Particular attention in our investigations has been given to mixed donor, macrocyclic systeir.s with emphasis on the recognition (and/or discrimination) of ions within the following industrially important groups: cobalt/nickel/copper; zinc/cadmium; and silver/lead (ref. 1).

Mixed donor macrocyclic ligands have proved to be especially suitable for use in studies of the above type since they tend not to yield complexes exhibiting the very high kinetic and thermodynamic stabilities that are, for example, characteristic of macrocyclic ligand complexes containing a $\mathrm{N}_{4}$-donor set (ref. 2); very high kinetic and/or thermodynamic stabilities tend to result in the corresponding solution measurements being less straight forward. Further, smaller ring macrocycles tend to favour 1:1 (metal:ligand) complexation, thus aiding the interpretation of solution results.

In a typical metal-ion recognition investigation, our procedure has been to chose a macrocyclic ligand which, based on analogy with known systems, might be expected to show preference for the ion of interest (ref. 3 ). Intuition usually plays a part at this stage! Following ligand synthesis, an investigation of its metal coordination chemistry, embracing metals of interest, is then carried out. Such a study has always incorporated the determination of the stability constants for the respective $1: 1$ complexes coupled with a range of other studies. The latter might include a combination of some or all of the following: the kinetics of complex formation and dissociation, calorimetric determinations of enthalpies of complexation, spectroscopic and spectrophotometric (UV-VIS, NMR and MS) determinations and, where appropriate (and possible), X-ray diffraction structure determination(s). An assessment of the possible factors influencing any observed metal-ion recognition behaviour is then made and, on this basis, a decision is taken as to what structural modification might be $\mathrm{c}$.rried out to 'tune up' this behaviour. The required ligand modification is then made and the cycle repeated. In this manner, it is usually possible to modify a ligand type progressively, using a trail and error approach, such that enhanced metal ion discrimination is induced. A given study may be associated with several such 'tuning' cycles.

The above strategy can be pictured as involving a structural matrix of ligands in which the axes are definad by, for example, macrocycle hole size, macrocycle donor set and degree of substitution on the macrocyclic ring. Previously, we have described studies in which each of these parameters have been employed independently to achieve enhanced recognition; however, clearly the strategy is more powerful when all three of these structural parameters are employed in the tuning process. Nevertheless, for simplicity, examples involving the variation of a single parameter will be given emphasis in the discussion which follows, as will studies that focus on silver(I) recognition.

\section{METAL ION RECOGNITION STUDIES}

\section{Variation of macrocycle ring size}

There are several well documented examples of metal ion recognition based on the tailoring of macrocyclic ring size to the radius of the metal ion of interest (ref. 1). As well as this, we have described a second mechanism based on ring size called 'dislocation discrimination', which depends on an abrupt change in coordination behaviour being induced towards one metal relative to another as the ring size is progressively altered (ref. 4). At the dislocation point, the coordination geometry change may result in an enhanced stability differential between the respective metal complexes. Ring size discrimination of both types has been well discussed previously and will not be further exemplified here.

\section{Variation of macrocycle substitution}

The variation of macrocycle substitution has been employed for the selective 'detuning' of the stabilities of individual metal complexes along a series of related complexes. 


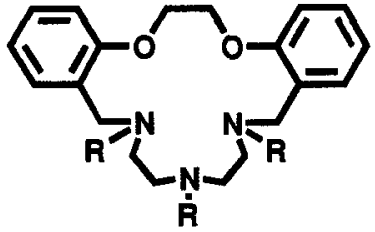

(1)

The effect of variation of $\mathrm{R}$ in the 17 -membered, $\mathrm{O}_{2} \mathrm{~N}_{3}$-donor structure represented by (1), on the respective stabilities of the cobalt(II), nickel(II), copper(II), zinc(II), cadmium(II), silver(I) and lead(II) is summar ised in Table 1 (ref. 5). Except for one case (see below), the data clearly show a decrease in the respective stability constants for the systems as methyl and benzyl substituents replace the NH protons of the parent $(1 ; R=H)$. Such a decrease has traditionally been ascribed to steric hindrance from the bulky $\mathbf{R}$ groups inhibiting complex formation; as expected, the effect is generally greater for the more bulky tribenzylated derivative. The exception is for silver(I) for which the $\log K$ values for each complex remains high.

TABLE 1. 'Substituent Detuning' - Effect of N-substituents on Log $K$ Values ${ }^{\mathrm{a}}$

\begin{tabular}{lccccccc}
\hline \multicolumn{1}{c}{ Ligand } & $\mathrm{Co}(\mathrm{II})$ & $\mathrm{Ni}(\mathrm{II})$ & $\mathrm{Cu}(\mathrm{II})$ & $\mathrm{Zn}(\mathrm{II})$ & $\mathrm{Cd}(\mathrm{II})$ & $\mathrm{Ag}(\mathrm{I})$ & $\mathrm{Pb}(\mathrm{II})$ \\
\hline $1 ; \mathrm{R}=\mathrm{H}$ & 7.6 & 10.0 & 14.4 & 7.5 & 8.7 & 8.7 & 8.1 \\
$1 ; \mathrm{R}=\mathrm{CH}_{3}$ & $<3.5$ & $<3.5$ & - & 5.1 & 6.1 & 10.3 & 6.6 \\
$1 ; \mathrm{R}=$ Benzyl & $<3.5$ & $<3.5$ & - & $\sim 3.5$ & $\sim 3.5$ & 9.3 & 4.3 \\
\hline
\end{tabular}

In $95 \%$ methanol, $I=0.1\left(\mathrm{Et}_{4} \mathrm{NClO}_{4}\right), 25^{\circ} \mathrm{C}$.

While the reason for the above behaviour remains uncertain, molecular models suggested that, in the case of silver(I), the substituted ligands could adopt 'interlocked' planar structures which are ideal for this ion. However, recent studies by Myerstein et al. (6) reveal a second explanation which is perhaps closer to the truth. These authors report that alkylation of the secondary amine groups of $\mathrm{N}_{4}$-donor macrocycles (as well as some open chain amines) results in preferential stabilisation of the +1 oxidation state of copper in preference to the +2 state of this ion; related stabilization of other metals in low oxidation states has also been documented.

It was concluded by the above authors that a major factor contributing to the above effect is the increased hydrophobic nature of the tertiary amine derivatives. This appears to have at least three consequences that will influence the relative stabilities of the two oxidation states: the $\sigma$-donating properties of the $\mathrm{N}$-methylated derivative is decreased due to the absence of hydrogen bonds of the type $\mathrm{M}-\mathrm{N}-\mathrm{H} \cdots \mathrm{O}$ (involving solvent); solvation energies will be lower for the $\mathrm{N}$-methylated complex due to its greater hydrophobic nature and larger radius; and steric hindrance may be increased leading to $\mathrm{M}-\mathrm{N}$ bond elongation and/or distortion of the inner coordination sphere.

Behaviour of this type, favouring the +1 state of silver(I) relative to the +2 states of the other metals listed in Table 1, might thus account for the observed stability changes associated with amine substitution in the present system.

\section{Variation of macrocycle donor set}

A considerable number of investigations have been reported that describe the interaction of transition and post-transition metal ions with mixed-donor macrocyclic ligands that include secondary amines (ref. 7). Nevertheless, studies of this type have tended to have received less attention than that given to macrocyclic systems in incorporating a single donor type. 
In this section the results of four case studies involving potentially tetra-, penta-, hexadentate and linked macrocycles, each incorporating secondary amines coupled with other donor types, are presented. A common theme through out these studies has been an emphasis on achieving discrimination for silver(I) over lead(II) metals which occur together in nature. Our most comprehensive metal-ion binding investigations of this type have involved the potentially pentadentate ligands of type (2). A discussion of these studies is presented first.

\section{Studies Involving Ligands of Type (2)}

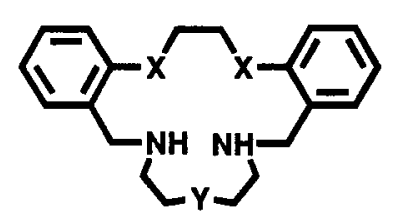

(2)

Before discussing the interaction of ligands of type (2) with silver(I) and lead(II); it is instructive to mention the behaviour of this 17 -membered macrocycle series towards copper(II) (ref. 8).

The $\log K$ data for the respective copper(II) complexes illustrates well the large effect that variation of donor set may have on the magnitude of the individual stability values. In this case a stability difference approximating to $10^{10}$ was achieved solely by variation of the donor type at three of the five potential donor sites. Thus, for this ligand system, the stability values ranged from log 6.5 for the copper complex of $(2 ; \mathrm{X}=\mathrm{Y}=\mathrm{O})$ to $c a \cdot \log$ 16.3 for that of $(2 ; \mathrm{X}=\mathrm{Y}=\mathrm{NH})$.

The systematic variation of the $\mathrm{X}$ and $\mathrm{Y}$ donors in the above ligand series has enabled extrac idinary discrimination for silver(I) over lead(II) to be achieved (ref. 9); the stability values obtained in this investigation are given in Table 2. For the 'parent' $\mathrm{O}_{2} \mathrm{~N}_{3}$-donor ligand, the log $K$ difference between the complexes of 'hese metals is less than an order of magnitude. This situation is only slightly improved when the $\mathrm{N}_{5}$-donor andiogue was employed (even though the absolute $\log K$ values are increased somewhat). In contrast, substitution of an oxygen donor in position $\mathrm{Y}$ (with $\mathrm{X}$ also oxygen) results in enhanced discrimination for silver(I) over lead(II). This appears to be a general phenomenon.

TABLE 2. Silver(I)/Lead(II) Discrimination: Effect of Donor Set on Log $K^{\text {a } V a l u e s ~ o n ~ S i l v e r(I) / L e a d(I I) ~}$ Discrimination (ref. 9)

\begin{tabular}{lccc}
\hline \multicolumn{1}{c}{ Ligand } & Silver(I) & Lead(II) & $\Delta \log K$ \\
\hline $2 ; \mathrm{X}=\mathrm{S}, \mathrm{Y}=\mathrm{S}\left(\mathrm{S}_{2} \mathrm{~N}_{3}\right)$ & 12.4 & $\sim 3.1$ & $\sim 9.4$ \\
$2 ; \mathrm{X}=\mathrm{S}, \mathrm{Y}=\mathrm{O}\left(\mathrm{S}_{2} \mathrm{~N}_{2} \mathrm{O}\right)$ & 10.3 & - & $\sim 7.3$ \\
$2 ; \mathrm{X}=\mathrm{S}, \mathrm{Y}=\mathrm{NH}\left(\mathrm{S}_{2} \mathrm{~N}_{3}\right)$ & $\sim 11.7$ & 8.0 & $\sim 3.7$ \\
$2 ; \mathrm{X}=\mathrm{O}, \mathrm{Y}=\mathrm{S}\left(\mathrm{O}_{2} \mathrm{~N}_{2} \mathrm{~S}\right)$ & 8.6 & 4.5 & 4.1 \\
$2 ; \mathrm{X}=\mathrm{O}, \mathrm{Y}=\mathrm{O}\left(\mathrm{O}_{3} \mathrm{~N}_{2}\right)$ & 7.1 & 5.5 & 1.6 \\
$2 ; \mathrm{X}=\mathrm{O}, \mathrm{Y}=\mathrm{NH}\left(\mathrm{O}_{2} \mathrm{~N}_{3}\right)$ & 8.7 & 8.1 & 0.6 \\
$2 ; \mathrm{X}=\mathrm{Y}=\mathrm{NH}\left(\mathrm{N}_{5}\right)$ & 10.3 & 9.4 & 0.9 \\
\hline
\end{tabular}

In 95\% methanol, $I=0.1\left(\mathrm{Et}_{4} \mathrm{NClO}_{4}\right), 25^{\circ} \mathrm{C}$.

When the differences in the $\log K$ values for all the ligand systems listed in Table 2 are compared, it is clear that substitution of a $\mathrm{N}_{2} \mathrm{Y}$-string (with $\mathrm{Y}$ equal to $\mathrm{O}$ or $\mathrm{S}$ ) for a $\mathrm{N}_{3}$-string consistently leads to an enhanced lowering of the stability of a given lead(II) complex relative to the corresponding silver(I) complex. In addition, this effect, coupled with the stepwise introduction of sulfur donors, culminates in much greater discrimination for silver(I) over lead(II). The relative affinities of these metals towards thioether sulfur undoubtedly reflects that 
silver(I) is b-class (or soft) while lead(II) is borderline. Indeed, in previous calorimetric studies we have demonstrated the marked affinity of silver(I) for thioether donors in systems of this type (ref. 10).

The final member of the above ligand series, incorporating an $\mathrm{S}_{3} \mathrm{~N}_{2}$-donor set, exhibits exceptional discrimination for silver(I) - the stability constant is now approximately $10^{9}$ in favour of silver!

$X$-ray diffraction structures of the silver(I) complexes of ligands of the above type with (a) $X=S, Y=O$ (ref. 9), (b) $X=S, Y=N H$ (ref. 11) and (c) $X=S, Y=S$ (ref. 12) show that the silver adopts a similar irregular five-coordinate geometry in each complex. The structure of the complex of $(2 ; \mathrm{X}=\mathrm{S}, \mathrm{Y}=\mathrm{O})$ is illustrated in Fig 1.

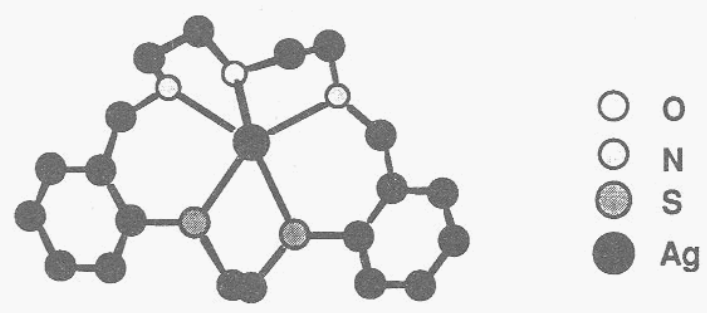

Fig. 1 The X-ray structure of the silver(I) complex cation of $(2 ; X=S, Y=O)$.

The macrocycles in these silver complexes wrap around the central metal such that the respective donor-tometal bond lengths are typical of those found in a range of other silver(I) complexes. The 'tight' five-coordinate geometries adopted in these complexes, differs from the structure of the lead(II) complex of the $\mathrm{N}_{3} \mathrm{~S}_{2}$-donor macrocycle (ref. 13). In this case, the metal adopts a seven-coordinate geometry, being bound to the five donor atoms of the macrocycle as well as to oxygens from two perchlorato anions; the latter occupy axial positions. The structure is illustrated in Fig. 2. In contrast to the situation in the silver complexes, the macrocycle in the lead complex adopts a flatter, more open, conformation - with the bound metal positioned below the macrocyclic cavity. Individual metal-donor bond lengths tend to be long and it is clear that the macrocycle binds less strongly to this ion. The structural evidence is thus in accordance with that from the solution studies.

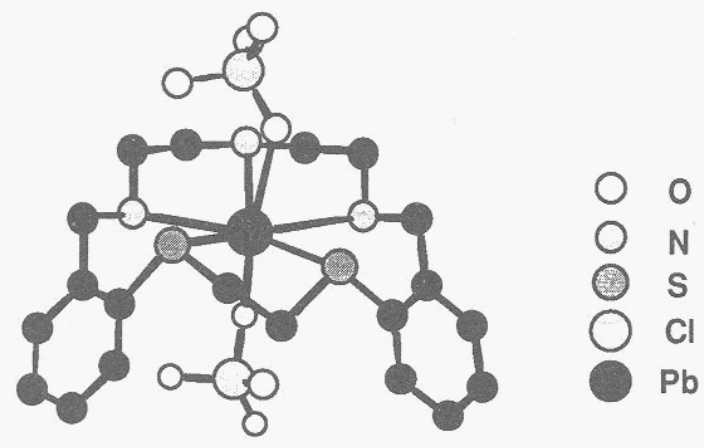

Fig. 2 The $X$-ray structure of the lead(II) complex cation containing $(2 ; X=S, Y=N H)$.

Overall, this study serves to illustrate the use of donor atom variation to achieve substantial discrimination. Further examples of the use of a similar strategy involving related ligand types follow.

\section{Studies Involving Ligands of Type (3)}

An investigation of the relative 1:1 complex stabilities of the 14- and 16-membered derivatives (3), incorporating trans $\mathrm{N}_{2} \mathrm{O}_{2^{-}}, \mathrm{N}_{2} \mathrm{~S}_{2^{-}}$and $\mathrm{N}_{4}$-donor sets, with cobalt(II), nickel(II), copper(II), zinc(II), cadmium(II), silver(I) and lead(II) has been carried out (ref. 14). The results are summarized in Table 3. 


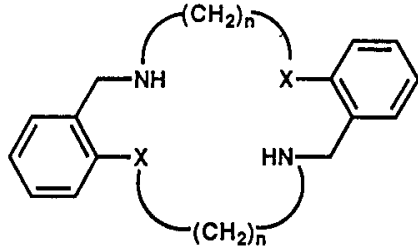

(3)
For these systems, despite the lack of data for individual complexes, the Irving-Williams stability order of cobalt(II) $<$ nickel(II) $<$ copper(II) $>$ zinc(II) appears to apply. Thus, at least towards these four metals, no unusual recognition behaviour was apparent. Nevertheless, it is noted that the relative $\log K$ values for the complexes of a given metal do, in general, reflect the nature of the donor atom $\mathrm{X}$ in (3); thus, as expected, donor-atom binding affinities of $\mathrm{N}>\mathrm{S}, \mathrm{O}$ are observed.

TABLE 3. $\log K^{\mathrm{a}}$ Values for the Complexes of the 14- and 16-Membered Macrocycles of Type (3) (ref. 14)

\begin{tabular}{|c|c|c|c|c|c|c|c|}
\hline $\begin{array}{l}\text { Ring Size } \\
\text { (Donor Set }\end{array}$ & Cobalt(II) & Nickel(II) & Copper(II) & Zinc(II) & Cadmium(II) & Silver(I) & Lead(II) \\
\hline $14\left(\mathrm{~N}_{2} \mathrm{O}_{2}\right)$ & $<4$ & $\sim 3.5$ & 7.4 & 4.2 & $<4$ & $-b$ & 4.4 \\
\hline $16\left(\mathrm{~N}_{2} \mathrm{O}_{2}\right)$ & $<4$ & $-b$ & 8.0 & 4.8 & $<4$ & 5.4 & $\sim 5.8$ \\
\hline $14\left(\mathrm{~N}_{2} \mathrm{~S}_{2}\right)$ & $<4$ & $-b$ & 9.9 & $-\mathrm{b}$ & -3.6 & 8.6 & $\sim 3.5$ \\
\hline $16\left(\mathrm{~N}_{2} \mathrm{~S}_{2}\right)$ & $<4$ & $-b$ & 8.8 & $<4$ & $<4$ & 9.3 & 4.5 \\
\hline $14\left(\mathrm{~N}_{4}\right)$ & $-b$ & $-b$ & 12.0 & $-^{b}$ & 5.6 & $-\mathrm{b}$ & 4.9 \\
\hline $16\left(\mathrm{~N}_{4}\right)$ & $-b$ & - b & 15.0 & 9.0 & 6.7 & 8.3 & $-\mathrm{b}$ \\
\hline
\end{tabular}

In $95 \%$ methanol, $I=0.1,\left(\mathrm{Et}_{4} \mathrm{NClO}_{4}\right)$, at $25^{\circ} \mathrm{C}$. ${ }^{\text {bPecipitation, slow approach to equilibrium or competing }}$ hydrolysis inhibited $\log K$ determination in this case.

In accordance with our previous discussion, both the 14- and 16-membered $\mathrm{N}_{2} \mathrm{~S}_{2}$-donor macrocycles show particular affinity for silver(I) and strong discrimination (approximately $10^{6}$ ) for this ion over lead(II). Both ligand systems incorporate alternating nitrogen and sulfur donor sequences and, once again, this is expected to favour silver(I) coordination over lead(II). Further, if the macrocycle coordinates in a planar fashion, then the silver(I) will be presented with a linear (trans) array of nitrogen donors - an arrangement potentially favourable for coordination - as exemplified by the structure of the $\left[\mathrm{Ag}\left(\mathrm{NH}_{3}\right)_{2}\right]^{+}$ion.

Finally, it is noted that increasing the macrocyclic ring size from 14- to 16 -membered for this $\mathrm{N}_{2} \mathrm{~S}_{2}$-donor system is associated with an increase in the absolute value of the binding constant towards silver(I). Once again, this is in agreement with expectations, since the larger ring should more closely match the moderately large covalent radius of the silver ion (if trans planar coordination occurs).

\section{Studies Involving Ligands of Tvpe (4)}<smiles>[X]c1ccccc1CNCc1ccccc1CNCc1ccccc1[X]</smiles>

(4)

We have also undertaken an investigation of the interaction of copper(II), silver(I) and lead(II) with the potentially hexadentate, 22-membered macrocyclic rings incorporating $\mathrm{N}_{2} \mathrm{O}_{4}^{-}, \mathrm{N}_{2} \mathrm{O}_{2} \mathrm{~S}_{2}$ - and $\mathrm{N}_{2} \mathrm{~S}_{4}$-donor sets, of type (4) (ref. 15). The $\log K$ values for the respective 1:1 complexes are listed in Table 4 . The step-wise substitution of ether oxygen donors by sulfur donors along this ligand series results in a moderate enhancement of the stabilities of the respective copper(II) complexes; thus indicating a weak preference of this ion for thioether-sulfur over ether-oxygen. However, for silver(I), the enhancement is much more significant and the absolute $\log K$

values are in each case higher than for the corresponding complexes of copper(II) [or lead(II)].

When the coordination chemistry of silver(I) is considered, this metal's preference for both linear amine coordination and soft donors are both able to be satisfied by the sulfur-containing ligands of type (4). 
${ }^{13} \mathrm{C} N M R$ spin-lattice relaxation $\left(\mathrm{T}_{1}\right)$ studies (together with inspection of the respective induced chemical shifts) have been used to probe the binding affinities of individual donor sites for this ligand series. Overall, the results correlate well with the observed stabilities of the individual silver(I) complexes.

TABLE 4. The Stabilities ( $\log K$ Values) $)^{2}$ of the Copper(II), Silver(I) and Lead(II) Complexes of Ligands of Type (4) (ref. 15)

\begin{tabular}{llrc}
\multicolumn{1}{c}{ Ligand } & Copper(II) & Silver(I) & Lead(II) \\
\hline $4 ; \mathrm{X}=\mathrm{O}, \mathrm{Y}=\mathrm{O}$ & $7.5(1)$ & $8.4(\mathrm{I})$ & $5.9(1)$ \\
$4 ; \mathrm{X}=\mathrm{O}, \mathrm{Y}=\mathrm{S}$ & $8.8(1)$ & $9.5(1)$ & $<4.5$ \\
$4 ; \mathrm{X}=\mathrm{Y}=\mathrm{S}$ & $9.7(1)$ & $12.5(1)$ & $<4.5$ \\
\hline
\end{tabular}

In $95 \%$ methanol $\left(I=0.1, \mathrm{Et}_{4} \mathrm{NClO}_{4}\right)$ at $25^{\circ} \mathrm{C}$.

In other studies, the members of this ligand series were employed as ionophores in competitive mixed-metal transport experiments across a bulk chloroform membrane. Details of the transport cell has been described elsewhere (ref. 16). The aqueous source phrase in each case contained equimolar concentrations of cobalt(II), nickel(II), copper(II), zinc(II), cadmium(II), silver(I) and lead(II). Transport was carried out against a back gradient of protons. Hexadecanoic acid was also present in the organic phase; this removes the need for the inorganic anion (nitrate) to be transported from the aqueous source phase into the organic phase. All three ligands yielded highly selective transport of silver(I) relative to the other ions present, with the highest transport efficiency being associated with the two sulfur-containing ligands. For each ligand system, silver was transported between approximately fifty and several hundred times more efficiently than the next metal to appear in the aqueous receiving phase.

\section{Linked Macrocyclic Ligands Systems}

The application of a protecting group strategy has resulted in efficient synthesis of new tri-linked $\mathrm{N}_{2} \mathrm{~S}_{2}$-donor macrocycles, incorporating 16 -membered rings, joined to a phloroglucinol or a 1,3,5-tribenzyl core by spacer linkages (ref. 17 ). The syntheses of these linked species is carried out from the corresponding 'parent' rings, incorporating differently protected nitrogen donors, as precursors. Structure (5) represents a typical tri-linked product. Once again, systems of this type (as well as their corresponding substituted 'monomers') readily complex silver(I): NMR titration data indicate that the tri-linked species (5) forms a 3:1 (metal:ligand) complex with silver(I) in 1:1 DMSO- $\mathrm{d}_{\sigma} / \mathrm{CDCl}_{3}$. A solid 3:1 (metal:ligand) complex of (5) has been isolated and characterized containing the (soft) copper(I) ion. The corresponding 1:1 complex of the N-benzyl-substituted 'monomeric' ligand has also been isolated and characterized by X-ray diffraction; the copper(I) in this species is associated with an irregular tetrahedral coordination geometry.

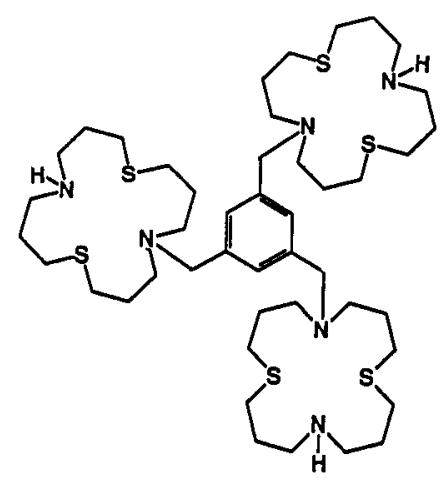

(5) 
Competitive solvent extraction (water/chloroform) experiments have been carried out involving equimolar concentrations of cobalt(II), nickel(II), copper(II), zinc(II), cadmium(II), silver(I) and lead(II) nitrates in the aqueous phase and (5) (at $1 \times 10^{-3} \mathrm{~mol} \mathrm{dm}^{-3}$ ) in the organic phase. Once again, strong discrimination for siiver(I) was observed - provided the individual metal ion concentrations were maintained in the range $10^{-4}-10^{-3}$ mol $\mathrm{dm}^{-3}$. Interestingly, at higher initial metal ion concentrations, the system became much less selective for silver. The reasons for this latter behaviour are unclear but are currently under investigation.

\section{ACKNOWLEDGMENT}

The author thanks his students and collaorators (see reference list) for their part in the work described above.

\section{REFERENCES}

(1) K. R. Adam, L. F. Lindoy, H. C. Lip, J. H. Rea, B. W. Skelton, and A. H. White J. Chem. Soc., Dalton Trans. 74 (1981); K. R. Adam, A. H. Leong, L. F. Lindoy, H. C. Lip, B. W. Skel'cn and A. H. White J. Am. Chem. Soc. 105, 4645 (1983); K. R. Adam, K. P. Dancey, A. J. Leong, L. F. Lindoy, B. J. McCool, M. McPartlin and P. A. Tasker J. Am. Chem. Soc. 110, 8471 (1988); K. R. Adam, M. Antolovich, D. S. Baldwin, L. G. Brigden, P. A. Duckworth, L. F. Lindoy, A. Bashall, M. McPartlin and P. A. Tasker J. Chem. Soc., Dalton Trans., 1869 (1992); K. R. Adam, M. Antolovich, D. S. Baldwin, P. A. Duckworth, A. J. Leong, L. F. Lindoy, M. McPartlin and P. A. Tasker J. Chem. Soc., Dalton Trans. 1013 (1993).

(2) L. F. Lindoy. The Chemistry of Macrocyclic Ligand Complexes, Cambridge University Press, Cambridge, U.K. (1989).

(3) L. F. Lindoy. Chapter 2 in Synthesis of Macrocycles: The Design of Selective Complexing Agents (R. M. Izatt and J. J. Christensen, Eds.) pp. 53-92, John Wiley, New York (1987).

K. R. Adam, P. H. Arshad D. S. Baldwin, P. A. Duckworth, A. J. Leong L. F. Lindoy, B. J. McCool M. McPartlin, B. A. Tailor and P. A. Tasker Inorg. Chem. 33, 1194 (1994) and references therein.

A. J. Leong, L. F. Lindoy, T. Strixner and P. A. Tasker, unpublished work.

G. Golub, H. Cohen, P. Paoletti, A. Bencini, L. Messori, I. Bertini and D. Meyerstein J. Am. Chem. Soc. 117, 8353 (1995);G. Golub, H. Cohen, P. Paoletti, A. Bencini and D. Meyerstein J. Chem. Soc., Dalton Trans. 2055 (1996); G. Golub, I. Zilbermann, H. Cohen and D. Meyerstein Supramolecular Chemistry 6, 275 (1996).

R. M. Izatt, J. S. Bradshaw, S. A. Nielsen, J. D. Lamb, J. J. Christensen and D. Sen Chem.Rev., 85, 271 (1985); R. M. Izatt, K. Pawlak, J. S. Bradshaw and R. L. Bruening Chem. Rev. 91, 1721 (1991).

K. R. Adam, D. Baldwin, P. A. Duckworth, A. J. Leong, L. F. Lindoy, M. McPartlin and P. A. Tasker J. Chem. Soc., Chem. Commun. 1124 (1987); K. R. Adam, M. Antolovich, D. S. Baldwin, P. A. Duckworth, A. J. Leong, L. F. Lindoy, M. McPartlin and P. A. Tasker J. Chem. Soc., Dalton Trans. 1013 (1993).

(9) K. R. Adam, D. S. Baldwin, P. A. Duckworth, L. F. Lindoy, M. McPartlin, A. Bashall, H. R. Powell and P. A. Tasker J. Chem. Soc., Dalton Trans. 1127 (1995).

(10) D. S. Baldwin, L. F. Lindoy and D. P. Graddon, Aust. J. Chem. 41, 1347 (1988).

(11) U. Kallert and R. Mattes, Inorg. Chim. Acta 180, 263 (1991).

(12) U. Kallert and R. Mattes Polyhedron, 11, 617 (1992).

(13) K. R. Adam, D. S. Baldwin, A. Bashall, L. F. Lindoy, M. McPartlin and H. R. Powell J. Chem. Soc., Dalton Trans, 237 (1994).

(14) A. J. Leong, L. F. Lindoy, D. C. R. Hockless, G. F. Swiegers and S. B. Wild Inorg. Chim Acta 246, 371 (1996).

(15) M-A. Ahearn, J. Kim, A. J. Leong, L. F. Lindoy, O. A. Matthews and G. V. Meehan J. Chem. Soc., Dalton Trans. accepted (1996).

(16) P. S. K. Chia, L. F. Lindoy, G. W. Walker and G. W. Everett Pure \& Appl. Chem. 65, 521 (1993).

A. M. Groth, L. F. Lindoy and G. V. Meehan J. Chem. Soc., Perkin Trans. 11553 (1996; 